\title{
PENGARUH ELEMEN TEMPO DALAM GAMELAN JAWA TERHADAP RESPONS EMOSI MUSIKAL
}

\author{
Djohan \\ Institut Seni Indonesia Yogyakarta
}

\begin{abstract}
Intense personal experience that provide insight into the nature of ife that involved emotion, cognitive, and social component happens when people listen to music. Those musical emotion responsses are expressed when the aesthetical value of music comes foward either through everyday music listening, or through intended performances. Therefore, this basic expenimental research was proposed to examined Javanese subjects, using the javanese gamelan musical instrument and was conducted in Yogyakarta. The purpose of the experiment was to obtain a better picture on how the element of tempo stimulation infuence the musical emotional responses of its listener. There were 32 subjects (musicians and nonmusicians) who are participating in this experiment. The study found that effocts of unmodified and modified tempo element towards the musical emotional responses or the musicians differs from those or non-musician. There are definitely differences provided by effects of the tempo element stimulation towards the emotional musical responses of the listeners, as well as showing that tempo is the most important element and potentially stimulate emotional musical responsses.
\end{abstract}

Keywords: javanese gamelan, tempo,emotional musical responsses.

\section{LATAR BELAKANG MASALAH}

Musik adalah aktivitas budaya yang sangat akrab dengan kehidupan manusia. Dalam berbagai bangsa dan dengan berbagai cara, musik adalah bagian yang tidak terpisahkan dari peristiwa-peristiwa penting dalam kehidupan, dari kelahiran sampai kematian. Sejak bayi, seorang anak mengenal musik dari senandung ibunya. Dalam masa kanak-kanak musik mewamai keceriaan dan permainan dunia kanakkanak. Musikjuga menjadi bagian kehidupan masa remaja dan masa muda. Dalam upacara perkawinan dan kematian, hampir setiap bangsa dan budaya juga memiliki musik pengiring pengantin atau pemakaman dengan tata bunyi dan komposisinya masingmasing.

Merriam (1964) menyatakan bahwa mungkin tidak ada aktivitas budaya manusia yang begitu meresap, menjangkau sampai ke dalam, membentuk, dan kadang mengendalikan perilaku manusia seperti musik. Jika diperhatikan dengan cermat, penggunaan musik dalam kehidupan seharihari tidak ada hablsnya. Musik terdengar d televisi, radio, pusat perbelanjaan, tempat ibadat, sekolah, acara olah raga, konser musik, upacara militer, dan di rumah. Miliaran dolar dihabiskan setiap tahun untuk berbelanja kaset, $C D, V C D$, tiket konser, dan alat musik. Musik dinikmati oleh segala lapisan dalam masyarakat tan pa terkecuali.

Dekatnya musik dengan kehidupan manusia kemudian menyebabkan tumbuhnya minat dan perhatian yang lebih besar terhadap musik, serta mendorong adanya penelitian tentang musik dalam kaitannya dengan berbagai disiplin ilmu. Orang mulai mempertanyakan apa yang dirasakan seseorang ketika mendengar suatu jenis musik tertentu, mengapa musik yang menjadi tema suatu film dapat 
sedemikian mempengaruhi orang-orang yang menontonnya, mengapa daerah tertentu memiliki karakter musik tertentu, dan masih banyak lagi.

Karena musik didengar kemudian dirasakan oleh pendengamya, maka unsurunsur psikologis memainkan peranan yang tidak sedikit. Salah satu disiplin ilmu yang dirasakan berkaitan erat dengan musik adalah psikologi. Hal ini dapat dipahami, mengingat dalam The American Heritage Dictionary (1982) dikatakan psikologi adalah karakteristik dari perilaku dan emosi individu, kelompok, atau aktivitas. Psikologi kemudian didefinisikan lebih luas dari hanya kajian perilaku. Dikarenakan musik adalah perilaku manusia maka secara keseluruhan kajian tersebut dinamakan psikologi musik. Dalam konteks ini, musik dan psikologi dipandang sebagai kata sifat sekaligus kata benda seperti halnya proses dan produk.

Beberapa penelitian yang permah mengkaji peran musik dalam kehidupan sehari-hari antara lain dilakukan oleh DeNora (1997) tehadap sekelompok perempuan Amerika dan Inggris, untuk melihat bagaimana musik dapat digunakan untuk mengolah, mempertahankan, meningkatkan kualitas emosi. Hasilnya menunjukkan bahwa secara nyata musik dirasakan sebagai sarana untuk menata dan meningkatkan kualitas diri baik pada aspek kognitif, emosi maupun fisik.

Dengan demlkian dapat dikatakan bahwa musik berkaitan erat dan berperan penting tehadap emosi dalam kehidupan sehari-hari. Penelitian-penelitian yang telah dikemukakan di atas sekaligus menguatkan hasil-hasil penelitian sebelumnya, seperti yang pernah dilakukan oleh Merriam (1964) tentang fungsi musik dalam kehidupan sehari-hari, atau penelitian Bertyne (1971), yang menemukan bahwa serumit, sesederhana atau sefamiliar apapun sebuah komposisi musik, tetap akan memberikan kontribusi terhadap respons emosi.

Sementara itu Peretz (2001) menguji emosi estetis dari musik yang muncul dalam otak manusia dan mengatakan bahwa keberadaan saraf tertentu juga telah tertata untuk emosi musikal tertentu pula.
Penemuan ofeh Schmidt dan Trainor(Peretz, 2001) menunjukkan bahwa aktivitas otak kiri meningkat saat mengekspresikan musik yang riang dan otak kanan membesar saat mendengarkan musik yang sedih. Aldridge (1996) mengatakan, karena musik dapat mempengaruhi orang yang sehat secara fisiologis dan psikologis, maka diasumsikan orang yang sakit juga akan merespons dengan cara tertentu.

Dengan kata lain, berbicara tentang musik sebenamya tidak mungkin dilepaskan dari kaidah-kaidah psikologi, karena aspekaspek psikologi secara otomatis akan menyertai musik ketika diperdengarkan. Bertyne (1971). Mandler (1984) dan Meyer (1956) memandang getaran sebagai faktor penting dalam pengalaman emosi saat seseorang mendengarkan musik. Ries (1969) juga mencatat bahwa amplitudo pernafasan seseorang berhubungan dengan respons afektif, sehingga terjadi korelasi yang positif jika seseorang mendengarkan musik yang la sukai. Emosi adalah salah satu aspek yang berperan besar dalam eksistensi manusia karena ia berhubungan dengan setiap aspek perilaku mulai dari persepsi, memori, belajar, mengambil keputusan sampai bertindak (Sloboda, 2001).

\section{DASARTEDR}

Dalam penelitian musik dan emosi, tujuan utama psikologi adalah memahami rentang mekanisme yang terjadi antara musik yang sampai ke teiinga pendengar dan emosi yang dialami atau dideteksi oleh seseorang, sehingga aspek emosi musik seharusnya juga menjadi kepentingan mendasar dalam musikologi. Gaver \& Mandler (1987) menggarisbawahi bahwa mempelajari musik akan sangat membantu dalam pemahaman emosi secara umum. Meskipun demikian, dari sisi musikologi, umumnya penjelasan yang dikemukakan para psikolog secara esensial dirasakan sangat kausal dan organismik. Kausal dalam artian mereka ingin menemukan anteseden suatu perilaku beserta mekanismenya, dan dikatakan organismik karena seliap bagian internal dari individu yang mendukung 
mekanisme tadi harus memperoleh perhatian khusus.

Secara teknis, analisis terhadap respons emosi yang ditimbulkan musik umumnya dilakukan berdasarkan evaluasi diri (self report) dari pendengar atau tergantung motivasi pendengarnya. Baik menurut Sloboda maupun Hargreaves dan North (2000), seseorang yang mendengar musik yang sama dalam waktu atau tempat yang berbeda, akan dapat menimbulkan respons emosi yang berbeda, karena pendengar dengan latar belakang budaya serta pengalaman musik yang berbeda akan memberikan respons secara berbeda pula.

Walau emosi telah dipelajari selama berabad sebelumnya, laporan mengenai emosi jarang sekali mempertimbangkan reakși emosi tehadap muslk (Zajonc, 1994). Konsep 'emosi musikal' sulit didefinisikan dalam teori emosi secara umum walau berbagal perbedaan respons emosi dari pengalaman musik dapat dltemukan di bawah Kata "emosi'. Sering pula ditemukan konsep emosi musikal dalam literatur, tetapi bagaimana 'musik mempengaruhi emosi' masih sulit untuk didefinisikan.

Emosl musikal berbeda dari emosi dalam pengalaman sehari-hari karena tidak memiliki konsekuensi yang sama dengan situasi emosi kehldupan sehari-hari. Kesamaannya adalah bahwa emosi musikal masih berakar dari dasar fisiologis yang dapat dirasakan oleh tubuh dan diperlihatkan melalui, air mata, menggigil atau gemetar, merinding, jantung yang berdebar dan berkeringat (Blood dan Zatorre, 2001).

Penelitian yang terkait dengan psikologi musik akhir-akhir ini menunjukkan bahwa pemisahan variasi parameter psikofisik tertentu dapat menimbulkan respons emosi yang berbeda (Campbell, Krysciak \& Schellenberg, 2000; Kaminska \& Woolf, 2000). Minat untuk mengkaitkan parameter psikofisik dengan elemen musik inl khususnya dilakukan dengan memanipulasi tempo (Crist,2000).

Bagaimana tanggapan yang diberikan seseorang terhadap musik yang la dengar tidak hanya tergantung pada aspekaspek lingkungan yang mempengaruhinya.
Dalam psikologi, masih diperlukan adanya pemahaman terhadap pertedaan individual (individual differences) yang terkait dengan kecenderungan kepribadian dan cri sifat yang tebentuk dalam diri seseorang. Jika pola yang ditunjukkan seseorang memperlihatkan adanya kualitas rasa yang membuat dirinya menjadi lebih peka, bebas, imajinatif, kreatif, dan eksploratif dalam menanggapi kesehariannya, maka orang tersebut dapat dikatakan memiliki rasa musikal (Sunardi, 2005).

Masih berbicara tentang respons emosi musikal yang terkait dengan pengaruh lingkungan, dapat đipahami jika orang Sumatera yang asing dengan budaya Jawa akan memberikan tanggapan yang berbeda ketika mendengarkan musik gamelan Jawa. Nada-nada gamelan Jawa yang pentatonik dalam tempo lambat mungkin akan terasa janggal di telinga orang Sumatera, selain itu secara psikologis tidak terdapat sense of belongingness kultural, sehingga mereka tidak dapat menikmatinya. Namun jika seseorang memiliki rasa musikal yang tinggi, akan sangat dimungkinkan bahwa nadanada yang asing sekalipun justru akan menggugah imajinasi, kreativitas, dan eksplorasi sebagai sebuah pengalaman musikal yang baru.

Gamelan Jawa juga adalah produk budaya yang tidak dapat dilepaskan dari pendukung budayanya yaknl masyarakat itu sendiri. Produk budaya bebentuk gamelan adalah wujud dari ekspresi ide, gagasan. atau perilaku masyarakat yang dituangkan dalam salah satu unsur budaya. Oleh karena itu eksistensi gamelan tidak dapat dipisahkan dari eksistensi dan perilaku seniman. Seniman itu sendiri merupakan salah satu kelompok sosial yang hidup bersama-sama dan berinteraksi dengan kelompok sosial lain.

Untuk memahami tatanan musik gamelan Jawa, perlu dipahami terlebih dulu bahwa musik secara rill merupakan bunyi yang diorganisir dalam bentuk tertentu dengan menggunakan elemen dasar berupa pitch (melodi), irama (tempo), timbre, dan dinamika. Parameter untuk menentukan ekspresi musikal (pada musik Barat) terlihat 
misalnya pada faktor modus, yaitu bahwa tangga nada mayor diasosiasikan dengan emosi positif dan tangga nada minor diasosiasikan dengan emosi negatif.

Konsep abstrak mengenai waktu dalam musik diterjemahkan sebagai irama dan manusia telah memiliki irama alamiah yaitu detak jantung. Tempo dalam kenyataannya secara biologis berhubungan dengan emosi. Bila tempo detak jantung cepat maka tingkat adrenalin meningkat, menimbulkan rasa cemas, takut, atau bergairah dan sebaliknya. Waktus adalah aspek fisika yang signifikan dalam musik, sedangkan durasi merupakan variabel psikologis yang berasosiasi dengan waktu. Hentakan/pukulan membagi periode waktu yang temporal ke dalam unit durasi yang sama. Kecepatan di mana terjadinya hentakan tersebut disebut tempo.

Sebuah melodi (lagu) yang diciptakan untuk suasana gembira, maka umumnya memiliki tempo cepat. Demikian pula sebaliknya lagu yang sedih biasanya akan menggunakan tempo lambat. Tempo memiliki pengaruh yang kuat terhadap melodi, karena sebuah lagu harus memiliki irama (tempo). Penelitian Jansma dan de Vries (1995) menyatakan bahwa elemen tempo dalam sebuah lagu merupakan salah satu karakteristik ekspresi emosi dari musik atau pengalaman musik bagi pendengar.

Musik gamelan Jawa secara praktis mulai menjadi bagian dari musik dunia walaupun lebih dalam konteks penyajian. Ada beberapa analisis mengenai teknis penyajian dalam gamelan oleh musisi Indonesia seperti misalnya Sumarsam (2003); Martopangrawit (1975). Demikian pula kajian kualitatif yang dilakukan oleh ilmuwan dan seniman barat seperti Rasa in Javanese Musical Aesthetics (Benamou, 1998); Kothong Nanging Kobak (Woiss, 2003). Kajian-kajian interdisiplin psikologi dan etnomusikologi yang terkait dengan gamelan Jawa justru belum banyak dilakukan oleh bangsa Indonesia sendiri.

Berkaitan dengan harapan untuk menelaah elemen musik (tempo) agar dapat memberikan sumbangan bagi kebutuhan musik dan psikologi terapan, maka pemilihan subjek pengrawit dan pandhemen dalam penelitian ini menjadi penting. Kedua kelompok ini diharapkan dapat memberikan gambaran mengenai perbedaan kepekaan kelompok "ahli" (pengrawit) dan kelompok "naif" (pandhemen) dalam memberikan respons terhadap elemen musik gamelan Jawa dalam penelitian ini. Diasumsikan, kelompok ahli (para musisi) adalah mereka yang nantinya teribat dalam penciptaan musik terapi, sehingga pengetahuan terhadap efek-efek musik mutlak dimiliki.

Sebagai salah satu aspek utama psikologi, emosi menjadi bagian yang penting dalam musik. Meskipun demikian kajian tentang emosi ditinjau dari kedua disiplin ilmu belum banyak dilakukan. Salah satu masalah yang dapat dijawab dengan pendekatan dari kedua sisi adalah bagaimana elemen-elemen musik dapat memengaruhi aspek-aspek psikologis. Penelitian yang ada sebelum inl menunjukkan bahwa elemen tempo adalah salah satu elemen terpenting dalam musik.

\section{METODE}

Penefitian eksperimental in i dilakukan dengan cara memperdengarkan gendhing Jawa dalam empat bentuk kepada dua kelompok subjek perlakuan penelitian. Dalam penelitian ini, emosi musikal lebih menunjuk pada pengalaman seseorang merespons musik yang didengamya atau respons yang terjadi ketika berinteraksi dengan musik. Dala respons emosi secara psikologis diperoleh melalui skala laporan diri dan skala deteksi emosi. Pengukuran respons emosi musikal didasarkan pada model pengukuran yang disusun oleh Osgood, Suci, dan Tannenbaum (1957) dengan teknik diferensi semantik untuk mengungkap dimensi afek atau perasaan yang berkaitan dengan suatu objek sikap.

\section{Subjek Penelitian}

Pengambilan sampel dalam penelitian dilakukan dengan metode purposive sampling. Karakteristik subjek adalah individu yang memiliki profesi sebagai 
seniman karawitan maupun ahli dalam bidang karawitan dan penggemar dengan memperhatikan usia dan pengalaman dalam bidang gamelan. Terdiri dari 16 pengrawit (musisi) dan 16 pandhemen (non-musisi) yang berusia $35-55$ tahun.

\section{Rancangan Eksperimen}

Penelitian eksperimen faktorial ini menggunakan desain repeated measure yang terdiri 4 perlakuan dengan 2 kelompok subjek. Dalam rangka counter balancing secara sistematik, masing-masing kelompok subjek dibagi menjadi 4 sub kelompok terdiri dari 4 subjek. Gendhing yang diperdengarkan dalam penelitian ini adalah gendhing yang sudah dikenal oleh semua subjek. Sehingga masing-masing subjek dalam setiap kelompok mendengarkan empat versi gendhing sebagai manipulasi. Maka rancangan eksperimen dalam penelitian ini seperti pada gambar di bawah ini

\begin{tabular}{|c|c|}
\hline Pengrawit & $\mathrm{X} 1.1 \times 2.1 \mathrm{Y} 1 \times 1.1 \times 2.2 \mathrm{Y}_{2} \times 1.2 \times 2.1 \mathrm{Y3} \times 1.2 \times 2.2 \mathrm{Y} 4$ \\
\hline Pandhemen & 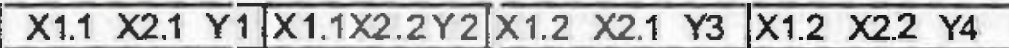 \\
\hline
\end{tabular}

Gambar.1.Rancangan eksperimen one way repeated measure

\begin{tabular}{|c|c|c|}
\hline \multicolumn{3}{|c|}{ Keterangan: } \\
\hline$x+1$ & $=$ fempoasli & $X_{1.1} X_{2.1}=$ TAP $($ TempoAsliPerunggu $)$ \\
\hline$\times 1.2$ & =tempamodifikasi & $\times 1.1 \times 2.2=$ TAB (TempoAsliBesi) \\
\hline$\times 2.1$ & = perunggu & - $\times 1.2 \times 2.1$ = TMP (Tempo Modifikasi Perunggu) \\
\hline$\times 22$ & =besi & $X 12$ X2.2 = TMB (Tempo Modfikasi Besi) \\
\hline $\mathbf{Y}$ & = respons emosi muskal & \\
\hline
\end{tabular}

Stimuli

Gendhing yang digunakan sebagai perlakuan dalam penelitian ini adalah gendhing Ladrang Agun-Agun. Dalam penelitian ini elemen tempo yang dimodifikasi adalah cepat lambatnya irama dalam gendhing tersebut. Semua gendhing untuk perlakuan direkam secara live menggunakan gamelan yang terbuat dari bahan perunggu dan besi. Durasi gendhing dalam tempo asil selama 03.38 detik dan ternpo modifikasi 05.12 detik. Total waktu yang dibutuhkan subjek untuk mendengarkan keempat gendhing yang tel ah manipulasi terse but adalah 18.10 detik.

\section{Prosedur}

Penelitian ini dapat dilaksanakan jika suasana hatt subjek berada dalam kondisi yang sama untuk menerima perlakuan penelitian. Untuk itu, 1 minggu sebelum perlakuan subjek mengisi skala deteksi suasana hati yang diadaptasi dari Profile of Mood State. Skala ini dimaksudkan untuk memantau jika terjadi perbedaan suasana hati pada subjek yang kemungkinan disebabkan oleh kelelahan atau faktor lainnya. efiti ini menjadi gambaran suasana hati subjek pra periakuan.

Data respons emosi musikal subjek diperoleh melalui self report dengan model semantic-differential dalam bentuk skala respons emosi yang diberikan kepada subjek saat perlakuan (setelah mendengarkan masing-masing gendhing). Selain itu juga digunakan skala deteksi emosi melalui rekarnan monifor televisi untuk mengamati perubahan ekspresi wajah dan anggota tubuh bagian atas selama diberi perlakuan. Observasi acak dilakukan bergantian terhadap ke empat subjek dalam satu kelompok perlakuan, sehingga abservasi tidak merekam ekspresi subjek demi subjek secara penuh dari awal hingga akhir eksperimen. $\mathrm{Hal}$ ini dilakukan agardiperoleh gambaran suasana kelompok secara keseluruhan. Kemudian dilakukan Diskusi Kelompok Terarah (DKT). Isi diskusi 
berkaitan dengan berbagai macam pengalaman emosi yang dirasakan subjek selama mendengarkan gendhing saat eksperimen.

Penelitian ini dilakukan di dalam ruang ukuran $3 \times 2,5$ meter yang dirancang dengan memberi batas penyekat antar keempat subjek agar tidak saling bertatapan. Ruang eksperimen dilengkapi pendingin ruang merk Shap dengan kekuatan $1 / 2$ PK. Wama dinding ruangan hijau muda terang dengan penerangan lampu $\mathrm{TL} 40$ watt dan bohlam puth 20 watt. Penerangan ini dimaksudkan agar rekaman video dari balik kaca satu arah tidak mengalami efek lower light yang mengakibatkan hasil gambar menjadi kabur.

Subjek diperdengarkan musik melalui 4 unit komputer dengan pirantl lunak Sound Fonge 6.0 menggunakan earphone. Penggunaan earphone dalam hal ini dikarenakan ruang eksperimen tidak sepenuhnya kedap suara walau bukan di tempat terbuka. Program Sound Forge 6 ini digunakan untuk memantau pada detik keberapa terjadi respons dari subjek. Respons dinyatakan secara langsung dengan menekan tombol keyboard komputer (penanda respons melalui huruf "m") saat mendengarkan gendhing. Semua tombol pada papan keyboard di tutup dengan karton tebal dan hanya satu tombol yang timbul.

\section{Peralatan}

Spesifikasi komputer yang digunakan adalah Intel Pentium 42 , $4 A$ Cache L2 1MB. MB Biostar Chipset Intel
865PE, RAM 256 MB PC 3200 Kingston DDR dual $\mathrm{CH}$, Hardisk 40 GB 7200 RPM, AGP $8 x$ Power Color GF 4Mx440 64MB, dengan sound card on board Codex 6 Ch. Setiap subjek menggunakan earphone dengan merk SONCM tipe SM-622M.V. Semua kelengkapan tersebut dimaksudkan agar suara yang didengar subjek dalam kualitas dan kondisi yang sama.

\section{HASIL PENELITIAN}

Data penelitian diolah berdasarkan analisis statistik yang menjelaskan pengujian kuantitatif dan hasil penelusuran secara kualitatif. Pada pembahasan analisis kuantitatif, dilakukan juga uji asumsi perlakuan untuk melihat kesesuaian antara data secara empiris yang diperoleh di lapangan dengan model analisisnya yang meliputi uj nomalitas sebaran data dan uj homogenitas varian. Selanjutnya, hasil penelusuran data kualitatif melalui Diskusi Kelompok Terarah (DKT).

\section{Hasil Pengujian Hipotesis Utama}

Berdasarkan analisis Tabel 1, maka hasil pengujian hipotesis mayor yang berbunyi "Terdapat pengaruh stimulasi elemen tempo dalam musik gamelan Jawa terhadap respons emosi musikal pendengar" secara signifikan diterlma, dengan $F$ hitung sebesar 4,968 $(p<0,05$ ). Artinya, ada pengaruh yang signifikan dari pemberian perlakuan stimulasi elemen terhadap respons emosi musikal.

Tabel 1. Ringkasan Repeated Measure

\begin{tabular}{|c|c|c|c|c|c|c|}
\hline Sumber Variasl & $J K$ & Db & Mx & $\mathbf{F}$ & $\mathbf{p}$ & R 타모 \\
\hline Tempo & 2096.281 & 1 & 2096.281 & 100.833 & $<000$ & .771 \\
\hline Tempo" Statua & 8224.031 & 1 & 8224.031 & 395584 & $<\infty 00$ & 930 \\
\hline Error(T ernpo) & 623.687 & 30 & 20.790 & - & - & - \\
\hline Timbre & 351,125 & 1 & 351.125 & 23.792 & $<.001$ & .442 \\
\hline Timbre Statug & 703.125 & 1 & 703.125 & 47.643 & $<.007$ & .614 \\
\hline Error( Timbor) & 442.750 & 30 & 14.758 & $\cdot$ & $=$ & - \\
\hline Tempo* Timbre & 536.281 & 1 & 536.281 & 50.722 & $<001$ & .628 \\
\hline Tempo* Tumbre Stalus & 52.531 & 1 & 52.531 & 4.968 & $<.050$ & .142 \\
\hline Erot (Tempo" TMmbre) & 317.187 & 30 & 10.573 & - & $=$ & - \\
\hline
\end{tabular}




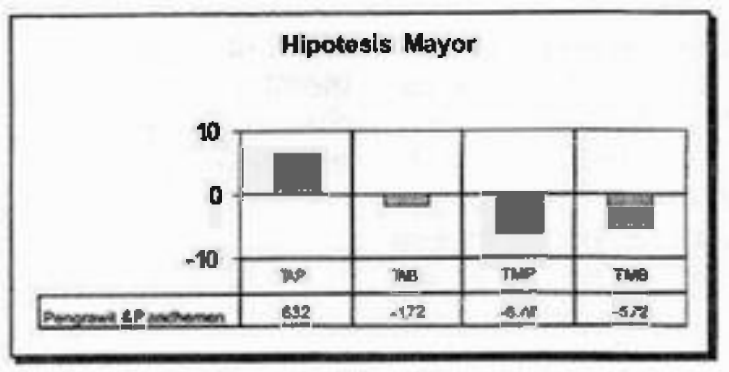

Gambar 2. Respons Emosi Musikal Pengrawit dan Pandhemen

Nilai pengrawit dan pandhemen digabung untuk menunjukkan perbedaan respons emosi musikal yang terjadi setelah masing-masing kelompok menerima perlakuan.

\section{Hasil Tambahan}

Hipotesis tambahan pertama berbunyi "Terdapat perbedaan pengaruh stimulasi elemen TAP dan TAB terhadap respons emosi musikal pendengar".

Tabel.2 Ringkasan Repeated Measure Antar Status

\begin{tabular}{|c|c|c|c|c|c|c|}
\hline Sumber Variași & Stimulus & $\mathbf{K}$ & b & $M K$ & $\mathbf{F}$ & $P$ \\
\hline \multirow[t]{3}{*}{ Stimulus } & Level 1 vs. Level 2 & 1755.281 & $t$ & 1755.281 & 80.464 & $<, 001$ \\
\hline & Level 2 vs. Level 3 & 731.531 & 1 & 731.531 & 16.529 & $<.001$ \\
\hline & Level 3 vs. Level 4 & 19.531 & 1 & 19.531 & .677 & $>.050$ \\
\hline \multirow[t]{3}{*}{ Stimulus " Status } & Leved $1 \mathrm{vs}$, Level 2 & 371.281 & 1 & 371,281 & 17.020 & $e_{(001}$ \\
\hline & Level 2 vs. Level 3 & 4117.781 & 1 & 4117.781 & 93.044 & $<001$ \\
\hline & Level 3 vs, Level 4 & 1140.031 & 1 & 1140.031 & 39.519 & $<.001$ \\
\hline \multirow[t]{3}{*}{ Emor(Stimulus) } & Level 1 rs. Level 2 & 654,438 & 30 & 21,815 & - & - \\
\hline & Level 2 vs. Level 3 & 1327.688 & 30 & 44.256 & - & - \\
\hline & Level 3 vs. Level 4 & 865,438 & 30 & 28.848 & - & - \\
\hline
\end{tabular}

Dari hasil analisis Tabel 2, dlperoleh F hitung sebesar 17,020 $(\mathrm{p}<0,01)$. Dengan demikian hipotesis tambahan pertama dalam penelitian ini diterima. Artinya stimulasi elemen TAP dan elemen TAB secara signifikan memberi perbedaan pengaruh terhadap respons emosi musikal pada pengrawit dan pandhemen. Respons emosi musikal yang dipengaruhi oleh elemen TAP dan $T A B$ pada pengrawit cenderung lebih menunjukkan respons emosi musikal yang positif dib andingkan dengan pandhemen.

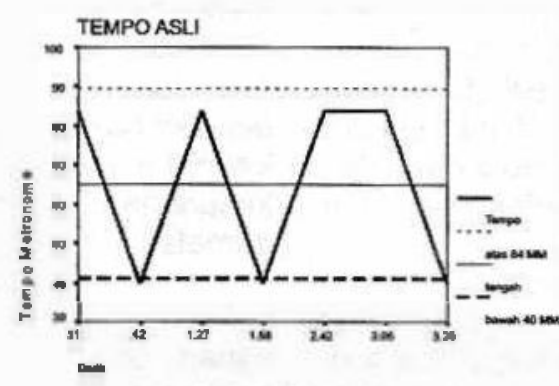

Gambar 3

Tempograph gamelan perunggu dan besi dalam tempo asli 
Hipotesis tambahan kedua berbuny: "Terdapat perbedaan pengaruh stimulasi elemen TMP dan TMB terhadap respons emosi musikal pendengar". Dari uji statistik diperoleh F hitung sebesar 39,519 $(p<0,01)$. Dengan demikian hipotesis tambahan kedua dalam penelitian ini diterima. Attinya elemen
TMP dan elemen TMB secara signifikan memberi perbedaan pengaruh terhadap respons emosi musikal pada pengrawit dan pandhemen.

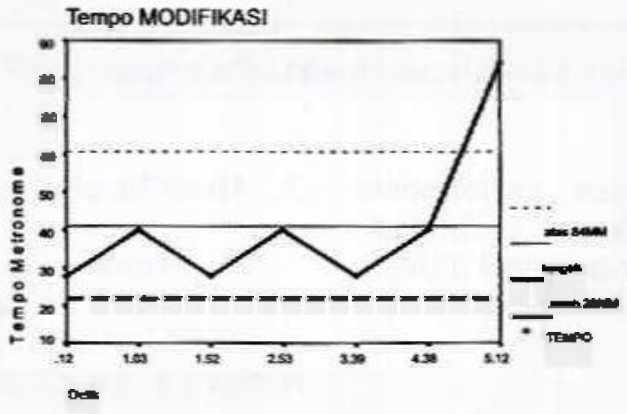

Gambar 4

Tempograph gamelan perunggu dan besi dalam tempo yang dimodifikasi

Selanjutnya, hipotesis tambahan ketiga yang berbunyi "Terdapaf perbedaan pengaruh antara stimulasi elemen TAP dan TMP dengan TAB dan TMB terhadap respons emosi musikal pendengar" juga diterima. Diperoleh F hitung sebesar 93,0444 $(p<0,01)$. Artinya pemberian stimulasi elemenTAPdanTMP maupunTABdanTMB secara signifikan memberi pengaruh terhadap respons emosi musikal pada pengrawit danpandhemen.

Berdasarkan perolehan data naratif melalui penelitian kualitatif, dilakukan telaah terhadap ringkasan DKT dan analisis isi. Hasil yang diperoleh menunjukkan bahwa teknik, kepekaan dan pengalaman para pengrawit secara nyata lebih terasah untuk merespons perbedaan antara gendhingyang dimainkan dalam tempo yang benar dari pada gendhing yang dimodifikasi. Beberapa dimensi seperti "biasa dan tidak biasa", "gojag gajeg dan mantep", "sesuai dan tidak sesuai", dengan segera tertangkap oleh parapengrawit.

Properti terbanyak yang dicatat dari DKT menunjukkan, para pengrawit dan pandhemen banyak kali mengungkapkan perasaan emosi mereka dengan kosa kata yang spesifik untuk menunjukkan ketidak nyamanan yang diakibatkan perubahan tempo. Ungkapan seperti wangun ora wangun, menunjukkan "ketidakrełaan" bahwa tempo sebuah gendhing mengalami modifikasi. Sebagai orang-orang Jawa, katakata yang berkaitan dengan kepantasan pada umumnya bermakna dalam karena hanya diungkapkan jika sangat terpaksa, Hal ini berkaitan dengan budaya Jawa yang sangat hati-hati dalam pengungkapan rasa serta cenderung menghindari konflik (Mulder, 2001; Endraswara, 2003).

Rangkaian hasil analisis seperti yang dikemukakan di atas menunjukkan bahwa pertanyaan penelitian pertama mengenai tempo sebagai elemen penentu dalam musik gamelan Jawa yang memilikl kekuatan untuk menimbulkan respons dengan berbagai persepsi bagi pendengarnya dapat dibenarkan. Dengan kepekaan, pengetahuan dan pengalaman mereka, kelompok pengrawit yang dalam kesehariannya main dan mendengarkan gamelan yang baik segera terpengaruh.

Penelitian ini juga menjawab beberapa tujuan penelitian yang terdiri dari tujuan penelitian pertama yaitu menguji pengaruh elemen tempo dalam musik gamelan Jawa tehadap respons emosi 
musikal pada pengrawit dan pandhemen di mana faktor musikal sebagai periakuan adalah elemen tempo yang dimodifikasi dengan pembalikan pada bagian-bagian cepat-lambat gendhing tersebut. Reaksi yang didapat dari perubahan tempo yang disengaja, baik pada gamelan perunggu maupun besi mendukung pendapat Sloboda (1991) bahwa pada beberapa kasus, musik dapat membangkitkan emosi secara intens.

Dalam penelitian ini kelompok pengrawit menunjukkan bahwa mereka memilki kepekaan untuk membedakan rasa musikal yang didengar sesuai dengan profesi yang digeluti setiap hari. Profesi seorang pengrawit dijalani dengan aktivitas lathan, rekaman, dan pentas. Hasil ini sesuai dengan pendapat Dowling (Tighe \& Dowling, 1986) bahwa kemampuan itu diperoleh karena pengalaman dan lingkungan budaya.

Perspektif antropologis dirasa penting karena musik gamelan Jawa secara geografis terbagi dalam beberapa kantong budaya d Jawa Tengah. Musik gamelan selain ada dalam budaya Keraton (misal, gaya Yogyakarta-Surakarta) juga ada of lingkungan budaya luar Keraton (KeduBanyumas). Budaya ini sangat jelas tercermin dalam interpretasi musik gamelan yang pada akhirnya menghasilkan perbedaan ekspresi pemain dan pendengar. Hal ini sekaligus menunjukkan bahwa terdapat pertedaan respons emosi musikal antara pengrawitdan pandhemen.

Respons emosi yang diberikan oleh kelompok pengrawit dan pandhemen dalam penelitian ini selain diperoleh secara langsung melalui 'penandaan' pada komputer (continuous responsses), mengisi dua skala, satu skala pengamatan yang dilakukan okh rater dan juga diskusi. Secara statistik, hipotesa dalam penelitian ini dapat diterima dengan has l yang signifikan.

Dari aspek budaya, respons emosi yang tidak tampak secara langsung juga dikarenakan kehidupan dalam masyarakat Jawa tampaknya tidak menyisakan banyak ruang bagi ekspresi individual. Ekspresi personal terutama yang mempenlihatkan emosi adalah hal yang tidak sopan, memalukan dan merupakan pelanggaran privasi orang lain. Selain itu juga dikatakan bahwa menghindari kemarahan memang akan kondusif bagi kemapanan psikologis (Mulder, 2001).

Secara neurologis, ekspresi wajah dapat dikatakan sebagai hasil dari sistem perilaku adaptif yang diimplementasikan melalui distribusi jaringan saraf termasuk sistem limbik dan secara khusus amygdala. Sementara ernosi musikal dapat terjadi dengan tiba-tiba secara otomatis melalui perubahan tanpa sengaja pada respons fisiologis dan perilaku. Konsepsi ini dihubungkan dengan kenyataan bahwa "Kita sering merasakan emosi yang terjadi pada kita bukan seperti apa yang kita pilih. Kita tidak menentukan kapan harus memiliki atau tidak emosi tertentu" (Ekman, dalam Ekman \&Davidson, 1994).

Namun demikian pada penelitian ini, ekspresi wajah yang direkam melaluj 'hidden camera' menunjukkan perubahan yang tidak signifikan untuk seluruh subjek kecuali beberapa subjek dari masing-masing kelompok. Demikian pula respons tubuh bagian atas tidak terlalu tampak, hal ini bisa dikatakan sebagai pengaruh dari budaya Jawa yang tidak spontan dalam merespons hal-hal yang belum diketahui secara pasti.

Penelitian inl menggunakan dua kelompok responden (pengrawitpandhemen) yang secara sosiologis berbeda di mana kelompok pengrawit kemungkinan besar memberikan respons karena faktor intra musikal sebagai bagian dari akumulasi referensi pengalaman, pengetahuan, dan kepekaan terhadap musik gamelan. Sebaliknya dengan kelompok pandhemen yang kemungkinan besar memberi respons karena faktor ekstra musikal. Sehingga melalui aspek sosiologis diharapkan fokus asosiasi pendengardengan musik dan emosi terjembatani

Akhirnya, penggunaan dua pendekatan dalam penelitian ini menjadi metode triangulasi dalam memberikan gambaran yang lebih komprehensif dan menjadi langkah awal untuk memverifikasi respons emosi musikal dan mengembangkan penelitian lebih lanjut dalam bidang psikologi musik. Namun 
demikian, dalam penelitian ini masih terdapat beberapa keterbatasan yang penting untuk penelitian sejenis, diantaranya pra pengukuran, alat ukur, skala deteksi emosi, karena itu pemahaman yang lebih baik, mungkin dapat menjelaskan reaksi emosi musikal yang lebih bermakna dan menyeluruh.

\section{PEMBAHASAN}

Penelitian dalam bidang Psikologi Musik, sudah banyak menemukan keterkaitan antara musik dan emosi. Namun banyak pula penemuan yang telah dilakukan sampai saat ini masih dalam taraf eksploratoris karena emosi tidak dapat disimpulkan secara sederhana, demikian pula musik sebagai produk perkembangan budaya. Konsekuensi lain adalah pernaknaan musik saat ini sudah harus mempertimbangkan aspek budaya. Seperti yang dikatakan Dowing \& Harwood (1986) bahwa dalam setiap budaya terdapat tandatanda musikal sebagai karakter simbolik yang dapat menimbulkan emosi.

Hipotesis dalam penelitian ini sesuai dengan teori emosi dari Meyer (1956) yang mengatakan bahwa ada elemen tertentu dalam musik seperti melodi atau irama yang dapat menghasilkan sesuatu d luar dugaan. Manipulasi elemen tempo dalam penelitian ini sangat terasa terutama saat dilakukan pembalikan pada bagian irama 1 dan irama 2. Walaupun perubahan yang terjadi tidak dilakukan dengan tiba-tiba tetapi respons emosi tampak dominan.

Demikian pula teori yang mengatakan bahwa elemen yang potensial menimbulkan efek relaksasi adalah tempo yang stabil atau perubahan secara berangsur-angsur juga tidak terbukti dalam penelitian ini (Wigram, Pedersen, Bonde, 2002). Karena perubahan tempo dengan transisi yang berangsur-angsur tetap menimbulkan respons tidak menyenangkan. Dari diskusi diketahui bahwa beberapa subjek bahkan tidak membedakan wama suara gendhing (perunggu dan besi) yang didengar karena perhatian dan perasaan mereka sedemikian kuat dipengaruhi oleh tempo.
Elemen tempo juga diakui oleh subjek sebagai "nyawa" atau "roh" dari sebuah musik. Karena apapun bentuk, jenis, dan teknik musik yang memadai baik melodi, irama, timbre dan dinamika, kalau terjadi penempatan tempo yang tidak tepat, maka musik yang dihasilkan akan berbeda sama sekali dengan yang diharapkan. Elemen tempo adalah elemen natural yang dimiliki dan dirasakan semua manusia tetapi dengan pemaknaan yang berbeda.

Beberapa subjek pengrawit mengakui bahwa ada rasa tidak menyenangkan pada beberapa gendhing yang diperdengarkan tetapi tidak reaktif dalam menyikapinya dikarenakan mereka sangat mengenal gendhing tersebut baik secara kognitif maupun afektif. Kondisi ini didukung oleh teori yang menyebutkan bahwa ada perbedaan respons emosi antara pendengar yang terlatih dan yang tidak terlatih. Terutama respons pengrawit, karena memiliki kemampuan analisis secara kognitif.

Sebagian subjek pengrawit bereaksi secara spontan terhadap perlakuan yang diberikan dan sebagian tidak bereaksi sama sekali. Hal itu bisa disebabkan oleh faktor individu yang potensial memengaruhi respons emosi seperti, pengalaman dalam bermain gamelan. Makin lama pengalaman bermain gamelan yang dirniliki pengrawit maka kepekaan dalam mendengarkan gendhing akan semakin akurat. Sementara bagi pandhemen, reaksi yang terjadi lebih ditentukan oleh pengalaman mendengar. Karena sebagai pendengar pasif dan tidak aktif bermain gamelan maka kepekaan dalam mendeteksi gendhing yang didengar belurn ten tu sebaik pengrawit.

Kedua hal tersebut sesuai dengan hasil penelitian yang ditemukan oleh Abeles dan Chung (1996). Hasil penelitian ini memperkuat penelitian sebelumnya bahwa tempo adalah elemen yang penting, begitu pula dengan respons yang ditimbulkannya. Respons emosi musikal lebih kuat terjadi karena keputusan pendengamya yang ban yak dipengaruhi oleh latihan musik. Oleh karenanya, penelitian yang berkaitan dengan pengaruh musik terhadap emosi membutuhkan pengetahuan sumber-sumber 
kausalitas (Collier, 2002). Oleh karenanya penelitian eksperimental sebaiknya dilengkapi studi 'impressionistic' tentang ekspresi, misal dalam sosiologi (Middleton, 1990), filsafat (Davies, 1994) dan psikoanalisa (Noy, dalam Feder, Karmel \& Pollock 1993).

\section{PENUTUP}

Dari hasil penelitian ini dapat ditarik beberapa kesimpulan secara umum bahwa respons emosi musikal merupakan bagian dari emosi estetis yang belum banyak dieksplorasi dalam bidang psikologi. Respons yang diakibatkan oleh stimuli elemen tempo hanya sebagian dari penelitian terhadap efek elemen musik lainnya. Walaupun hanya satu elemen musikal yang digunakan dalam penelitian ini, namun reaksi berupa respons emosi yang ditimbulkannya menunjukkan perbedaan signifikan antara subjek pendengar. Hasil eksperimen ini juga memberikan informasi mengenai pentingnya elemen tempo sebagai stimulator respons emosi musikal. Terujinya hipotesis yang diajukan dalam penelitian ini maupun ungkapan kualitatif yang terucap dari subjek penelitian menunjukkan hal tersebut.

Secara keseluruhan, pengolahan terhadap rangkaian eksperimen ini menunjukkan bahwa stimulasi elemen tempo asfi perunggu dan tempo asli besi serta tempo modifikasi perunggu dan tempo modifikasi besi berpengaruh secara sangat signifikan terhadap respons emosi musikal pendengarnya. Selain itu, kelompok pengrawit menunjukkan kepekaan yang lebih tinggi dari pada kelompok pandhemen dalam membedakan tempo baik asli maupun modifikasi.

Penelitian ini diharapkan dapat memberi masukan bagi pengembangan disiplin Psikologi Musik di Indonesia walaupun saat ini tidak dimaksudkan untuk diaplikasikan atau menjawab semua pertanyaan yang terkait dengan respons emosi musikal. Respons emosi musikal adalah terminologi respons emosi yang tidak terdapat dalam mainstream psikologi emosi umum. Berdasarkan pemahaman dari aspek antropologis, sosiologis maupun filosofis musik yang lebih dikenal adalah terminologi emosi estetis. Sementara istilah emosi musikal adalah salah satu bagian dari terminologi terse but. Respons emosi musikal memiliki sumbangan atau paling tidak akan melengkapi pengembangan pengetahuan tentang emosi dan membuka bidang kajian baru yaitu psikologi musik.

Hasil akhir penelitian ini melengkapi hasil-hasil penelitian yang pemah dilakukan terhadap musik Sarat bahwa tempo adalah elemen yang penting dalam musik karena respons emosi musikal pendengar musik gamelan Jawa dalam penelitian ini teruji sangat kuat dipengaruhi oleh elemen tempo. Apabila penelitian sejenis dapat dilakukan d berbagai wilayah Nusantara maka pengembangan selanjutnya adalah pada aplikasi terapi musik yang khas Indonesia atau pemanfaatan di luar kepentingan musik. Dengan begitu terbuka kemungkinan luas disiplin Psikologi Musik Indonesia untuk sejajar dengan disiplin sejenis secara intemasional.

Hal ini sekaligus menunjukkan bahwa masih terbuka kesempatan luas untuk menggali potensi seni budaya lokal yang bermanf aat tidak hanya bagl pengembangan ilmu pengetahuan teiapi juga bagi makna sehat bangsa ini. Oleh karena itu peneliti merekomendasikan kepada peneliti bidang psikologi dan musikologi agar dapat lebih banyak berperan dengan mulai menyelidiki aspek saintifik dan aplikatif dari potensi seni budaya Nusantara.

Sesuai dengan hasil penelitian ini baik secara metodologis maupun teoretis sebagai pendukung yang penting. kesempatan untuk melakukan interdisiplin juga perlu ditumbuh-kembangkan di lembaga Pendidikan Tinggi. Mengingat selama ini penelitian lintas disiplin masih belum banyak dilakukan ataupun didukung oleh lembaga Pendidikan Tinggi. Topik interdisiplin yang digali dari budaya Nusantara secara langsung akan memberikan warna dan menunjukkan kepada dunia luar bahwa bangsa iní memiliki keistimewaan saintifik melatui seni budaya tradisinya. 
Oleh karena itu metode penelitian dan cara berpikir yang non-paradigmatik dirasa perlu dikembangkan. Agar situasi dan suasana kehidupan akademis selalu inovatif maka hal-hal yang dirasa baru tetapi bermanfaat perlu diperhatikan secara seksama. Secara khusus bagi pengembangan disiplin Psikologi Musik, penelitian yang bersifat dasar masih pertu dilakukan. Ke depan diharapkan peneliti Indonesia dapat berperan secara aktif melalui hasil penelitiannya bagi pengembangan psikologi musik secara global.

\section{DAFTAR PUSTAKA}

Abeles, H.F. \& Chung, J.W. 1996. Responsses to music. In Handbook of music psychology (2 ${ }^{\text {nd }}$ ed.) (ed. D.A.Hodges), pp.285-342. San Antonio,TX: IMR Press.

Aldridge, D.1996. Music therapy research and practice in medicine: From out of the silence, London: Jessica Kingsley.

Benamou, M. 2001. Rasa in javanese musical aesthetics. $P h D$ dissertation: Musicology. Ann Arbor, MI: UMI Company.

Berlyne, D. E. 1971. Aosthetics and psychobiology. New York: Appleton Century-Crofts.

Blood, A.J., \& Zatorre,R.J.2001. Intensely pleasurable responses to music correlate with activity in brain regions implicated reward and emotion. Proceedings of National Academy of Sciences, 98, 11818-23.

Campbell, R.J., Krysciak, A.M.\& Schellenberg, E. 2000. Perceiving emotion in melody: Inferactive effects of pitch and rhythm. Music Perception, 18, 155-171.

Collier, G.L. 2002. Affective synesthesia: Extracting emotion space from simple perceptual stimulus. Motivation and Emotion, 20, 1-32
Crist, M.R. 2000. The effect of tempo and dynamic changes on listener's abiiity to identify expresive performances. Contribution to Music Education, 27, 63-77.

Davies, S. 1994. Musical meaning and expression. Ithaca, New York: Cornell University Press.

Dowling, W. J \& Harwood, D.L. 1986. Music Cognition. New York: Academic Press.

De Nora,T.1997. Music and erotic agencysonic resources and social-sexual action. Body and Society, 3, 4365.University Press.

Ekman, P \& Davidson RJ. 1994. The nature of emotion: Fundamental questions. NY.

Endraswara. S. 2003. Budi pekerti dalam budaya jawa. Yogyakarta: PT. Hanindita Graha Widya.

Feder, S., Karmel, R. L. and Pollock, G. H. (Eds) 1993, Psychoanarytic Explorations in Music. Madison, Connecticut: International Universities Press.

Gaver, W.W.\& Mandler,G. 1987. Play it again, Sam: On liking music. Cognition and Emotion, 1, 259-82.

Hargreaves,D., \& North,A.C. 2003. The social psychology of music. NY. Oxford University Press.

Jansma, M, \& Vries, Bart de.1995. Muziek en emotie. In: Evers, Jansma, Mak, De Vries (Eds). Muziekpsychologie. (pp. 204-222). Assen: Van Gorcum.

Kaminska, Z \& Woolf, J. 2000. Melodic line and emotion: Cooke's theroy revisited. PsychologyofMusic, 28, 133-153.

Mandler, G.1984. Mind and body: Psychology of emotions and stress. NY: Norton.

Martopangrawit, R.L. 1975. Tjatatan-jjatatan pengetahuan karawitan. Surakarta: Pusat Kesenian Djawa Tengah dan Dewan MahasiswaASKI. 
Merriam, A.P 1964. The anthropology of music. Evanston,lL: Northwestern University Press.

Meyer, L. B. 1956. Emotion and meaning in music, Chicago: University of Chicago Press.

Middleton, R 1990. Studying popular music. Milton Keynes, UK: University Press.

Mulder, N. 2001. Mistisisme Jawa ideologi Indonesia. Yogyakarta: Lkis.

Osgood,CE, Suci,G.J \& Tannenbaum,P.H. 1957. The measurement of meaning. Urbana,L- University of Illionis Press.

Ries, H.A. 1969. GSR and breathing amplitude related to emotional reactions to music. Psychonomic Science, 14(2), 62-64.

Sloboda, J.A 1991. Music structure and emotional responsse: some empirical findings. PsychologyofMusic, 19, 110 120.

Slobodia, JA. \& O Neill, S.A. 2001. Emotions in everyday listening to music. I PN. Juslin \& J.A. Sloboda (Eds.),(2001) Music and emotion: theory and research (pp.415-30). NY: Oxford University Press.

Sumarsam, 2003. Gamelan: interaksi budaya dan perkembangan musikal of Jawa. Yogyakarta. Pustaka Pelajar.
Sunardi,St. 2005. Ayo nembang: kumpulan tembangtembang untuk pendidikan (in press).

Tighe, T.J. \& W.J. Dowling (Eds) 1986 Psychology and Music: The understanding of melody and thythm. Hillsdale, NJ, Erlbaum.

Weiss,S. 2003. Kothong nanging kebhak. Empty yet full : Some thoughts on embodiment and aesthetic in javanese performance. Asian Music, 34/2, 2149.

Wigram, T. Pedersen, I,N., \& Bonde, $O, L$ 2002. A comprehensive guide to Music Therapy : theory, clinical practice, research and training. London: Jessica Kingsley Publishers.

Zajonc, R.B. 1994. Emotional expression and temperature modulation. in S.H.M. Van Goozen, N.E. Van de Poll, \& J.A. Sergeant (Eds). Emotion: essays on emotion theory, pp.3-27. Hillsdale, NJ: Earlbaum.

Zenatti, A 1993. Children's musical cognition and taste, in: Tighe, T.J. \& Dowling, W.J. (Eds) Psychology and Music. The Understanding of melody and thythm, pp. 177 196. Hillis dale, NJ Erlbaum. 